\title{
Oxidation of human serum albumin exhibits inter-individual variability after an ultra-marathon mountain race
}

\author{
YPATIOS SPANIDIS $^{1}$, ALEXANDROS PRIFTIS ${ }^{1}$, DIMITRIOS STAGOS ${ }^{1}$, \\ GEORGE A. STRAVODIMOS ${ }^{2}$, DEMETRES D. LEONIDAS ${ }^{2}$, DEMETRIOS A. SPANDIDOS ${ }^{3}$, \\ ARISTIDES M. TSATSAKIS ${ }^{4}$ and DEMETRIOS KOURETAS ${ }^{1}$
}

${ }^{1}$ Laboratory of Animal Physiology, and ${ }^{2}$ Laboratory of Structural and Functional Biochemistry, Department of Biochemistry and Biotechnology, University of Thessaly, Larissa 41500; ${ }^{3}$ Laboratory of Clinical Virology, University of Crete, Medical School, Heraklion 71409; ${ }^{4}$ Department of Forensic Sciences and Toxicology, Medical School, University of Crete, Heraklion 71003, Greece

Received January 6, 2017; Accepted March 14, 2017

DOI: $10.3892 /$ etm.2017.4268

\begin{abstract}
The aim of this study was to examine the oxidation of human serum albumin (HSA) caused by oxidative stress following exhaustive and demanding exercise, such as an ultra-marathon race. For this purpose, blood samples from 12 adult runners who underwent a $103 \mathrm{~km}$ mountain ultra-marathon race were collected before the race, and also at 24,48 and $72 \mathrm{~h}$ post-race. HSA was partially purified using affinity chromatography and consequently subjected to western blot analysis in order to determine the levels of disulfide dimers indicating oxidation. For reasons of comparison, the results were correlated with those from a previous study, in which the same samples were analyzed using different oxidative stress markers. The results revealed a good correlation between albumin dimers and protein carbonyls at all time points, while there was also a significant correlation with static oxidation reduction potential at $24 \mathrm{~h}$, and a negative correlation with capacity oxidation reduction potential at 24 and $48 \mathrm{~h}$. In addition, an individual analysis of albumin dimers exhibited great inter-individual differences, indicating the variation of HSA oxidation between different athletes. Namely, in some athletes, HSA seemed to be the main oxidation target of serum proteins,
\end{abstract}

Correspondence to: Professor Demetrios Kouretas, Laboratory of Animal Physiology, Department of Biochemistry and Biotechnology, University of Thessaly, Viopolis, Larissa 41500, Greece

E-mail:dkouret@uth.gr

Abbreviations: CAT, catalase; EDTA, ethylenediamine tetraacetic acid; GSH, glutathione; HSA, human serum albumin; PC, protein carbonyls; ROS, reactive oxygen species; sORP, static oxidation-reduction potential; TAC, total antioxidant capacity; TBARS, thiobarbituric acid reactive substances

Key words: albumin, oxidative stress, exercise, ultra-marathon mountain race, protein carbonyls while in other athletes, there was even a reduction of HSA. This inter-individual variability in the oxidation of HSA may suggest that different interventions (e.g., through diet) may be required in order to confront the effects on athletes following strenuous exercise. On the whole, this study suggests the importance of the assessment of albumin dimers as a predictive marker for exercise-induced oxidative stress.

\section{Introduction}

The association between physical exercise and the increase in the production of free radicals has been well established $(1,2)$. Free radicals are products of normal metabolism and include mainly reactive oxygen species (ROS), such as superoxide radical $\left(\mathrm{O} 2 \bullet^{-}\right)$, hydroxyl radical $(\mathrm{OH} \bullet)$, and peroxyl radical ( $\mathrm{RO} 2 \bullet$ ), as well as reactive nitrogen species (RNS), such as nitric oxide (NO) and the peroxynitrite radical (ONOO•) (3). The excessive production of ROS may affect several cell functions, such as the regulation of signaling pathways and is involved in gene expression and apoptosis (4). ROS generation is affected by endogenous sources, such as the mitochondrial respiratory chain, inflammation and cytochrome P450 activity (5), or exogenous sources, such as smoking, air pollution and UV light (6). However, ROS generation during exercise and in particular during aerobic exercise, is believed to be caused by the increased uptake of oxygen from the active peripheral skeletal muscle tissues (2). Excessive ROS production may lead to a pathological condition known as oxidative stress (7). For the determination of oxidative stress levels following exercise, a number of oxidative stress markers are assessed, such as the levels and activity of antioxidant enzymes and molecules, oxidative DNA damage, lipid peroxidation and protein oxidation (8-12).

As regards protein oxidation, this is usually assessed by measuring protein carbonyl (PC) levels in plasma. The most abundant protein in plasma (approximately 50\% of total protein) is human serum albumin (HSA) $(13,14)$. HSA is a multifunctional, non-glycosylated globular protein composed of 585 amino acids with a molecular weight of $66 \mathrm{kDa}$, and is mainly synthesized in the liver (15-17). The structure of the 
protein contains a center made up of hydrophobic radicals used as a binding site for ligands, while the outer part is composed of hydrophilic ligands. More specifically, albumin binds to and transfers several ligands, such as bilirubin, hormones, metal ions and xenobiotics (18).

In addition, HSA possesses a free thiol group in Cys34, and thus it may function as an extracellular antioxidant by scavenging ROS $(19,20)$. Davies and co-workers published a series of studies explaining in detail the association between oxidative damage and the increased proteolytic susceptibility of bovine serum albumin (BSA) (21-24). Particularly, albumin residues contain cysteine and methionine sulfhydryl groups reacting with peroxides, leading to thiol oxidation $(25,26)$. It is considered that albumin acts as an antioxidant, since Cys34 of albumin, a cysteine that represents approximately $80 \%$ of the total thiol content in plasma, scavenges ROS (27). However, under oxidative stress conditions, albumin is oxidized and Cys34 forms a disulfide with low molecular weight thiols, such as cysteine. Thus, the oxidation caused by free radicals may affect the molecule's conformation and structure (28). Moreover, albumin dimers have been reported as products of peroxidation caused by free radicals, and consequently they may be used as a marker of oxidative stress (29). Furthermore, since a number of studies have reported the association between the oxidation of albumin and exercise $(20,28,30)$, the determination of albumin dimer levels may be a good indicator of oxidative stress in athletes.

Therefore, the present study focused on the determination of the levels of albumin dimers in the plasma of runners participating in an exhaustive mountain marathon race, 'Olympus Mythical Trail 2015'. This mountain marathon race covers a distance of $103 \mathrm{~km}$ in the mountain of Olympus in Northern Greece. It is considered to be one of the most demanding routes worldwide, since it includes a 7,200 m elevation gain and a highest altitude of $2,906 \mathrm{~m}$, while $40 \mathrm{~km}$ of the route take place at an altitude higher than 2,000 m.

Moreover, in one of our previous studies, protein oxidation in the plasma of these runners was determined spectrophotometrically by phosphatidylcholine assay in order to assess the redox status from 24 to $72 \mathrm{~h}$ post-race (31). Thus, we also examined the correlation between the levels of HSA oxidation with the PC levels of total plasma protein, as well as with other oxidative stress markers. The determination of these correlations would help to determine whether HSA oxidation is a good marker for the assessment of oxidative stress following exercise.

\section{Materials and methods}

Subjects. Twelve adult male runners aged $41.1 \pm 3.2$ years, voluntarily participated in the present study (height, $1.78 \pm 0.02 \mathrm{~m}$; weight $72.9 \pm 2.0 \mathrm{~kg}$ ). The subjects were informed not to receive any anti-inflammatory medicines or nutritional supplements and they were all familiar with mountain running.

The participants visited the Litohoro Health Center, located close to the starting point, $8 \mathrm{~h}$ before the race in order to complete a health and activity questionnaire, and their anthropometric parameters were taken. Moreover, written informed consent to participate in the study was provided by all the participants prior to blood collection. Body mass was measured to the nearest $0.5 \mathrm{~kg}$ (beam balance 710; Seca, Birmingham, UK) with the subjects lightly dressed and barefoot. Standing height was measured to the nearest $0.5 \mathrm{~cm}$ (Stadiometer 208; Seca).

All the performed procedures were in accordance with the Helsinki declaration of 1975 as revised in 2000 and approval was received by the human subjects committee of the University of Thessaly.

Description of the race. The volunteers participated at one of the most extreme mountain ultra-marathons worldwide known as the 'Olympus Mythical Trail', on July 4-5th 2015 in Olympus Mountain in Northern Greece. The peculiarity and difficulty of the race lies on the fact that it is a $103 \mathrm{~km}$ 'loop'-type route with a total ascent (positive height difference) of 7,200 m (more than twice the altitude of Olympus Mountain), while approximately $40 \mathrm{~km}$ of the route are at an altitute above $2,000 \mathrm{~m}$. The starting and ending points are placed at Litohoro town in Greece. The route consists mostly of paths (95\%) and dirt (5\%) and is divided into 18 checkpoints. The maximum time allowed for race completion was $28 \mathrm{~h}$.

Subject performance. Following the completion of the race, 8 out of 12 participants managed to finish the race (individuals no. $1,2,3,4,5,6,9$ and 11), while 2 of them gave up at the 70 th $\mathrm{km}$ (individuals no. 7 and 10) and the other 2 at the 60 th $\mathrm{km}$ (individuals no. 8 and 12). The mean running time of the athletes was $19.57 \pm 1.09 \mathrm{~h}$.

Blood collection and processing. The blood samples $(10 \mathrm{ml})$ were drawn from a forearm vein with the subjects in the seated position at four different time points; $8 \mathrm{~h}$ before the competition (pre-race sample) and at 24, 48 and $72 \mathrm{~h}$ post-race. The samples were stored in ethylenediamine acid (EDTA) tubes and centrifuged at $1,370 \mathrm{x} \mathrm{g}$ for $10 \mathrm{~min}$ at $4^{\circ} \mathrm{C}$ to divide the erythrocytes from the plasma. The plasma lysates were then stored at $-80^{\circ} \mathrm{C}$ prior to biochemical analysis.

Albumin determination assay. Albumin was determined spectrophotometrically at $628 \mathrm{~nm}$, based on the formation of a coloured complex with bromocresol green reagent (BCG) solution in a $0.075 \mathrm{M}$ succinate buffer ( $\mathrm{pH} 4.20)$ (32).

Partial purification of albumin. For sample preparation, 1 volume of plasma was diluted in 50 volumes of a $0.1 \mathrm{M}$ HEPES buffer ( $\mathrm{pH}$ 7.0), containing $1 \mathrm{mM}$ EDTA (Buffer A). The column was equilibrated by $10 \mathrm{ml}$ of Buffer A using an AKTA prime protein purification system (AKTA purifier UPC 10; GE Healthcare Bio-Sciences AB, Uppsala, Sweden), and the diluted sample was then applied to a Blue Sepharose column (1 ml) (HiTrap Blue HP; GE Healthcare Bio-Sciences AB). The column was washed with $10 \mathrm{ml}$ of Buffer A, and the purified HSA was eluted and selected in a test tube using a $10 \mathrm{ml}$ solution of $0,15 \mathrm{M} \mathrm{KCl}$ containing Buffer A (Buffer B).

Western blot analysis of albumin and albumin dimers. Protein concentration in plasma following the purification of the samples was measured using the Bradford reagent (Sigma-Aldrich, St. Louis, MO, USA). The calculation of the albumin concen- 
tration was made by using an albumin standard curve. Albumin monomers and dimers were then determined in the purified plasma samples by western blot analysis using a non-reducing SDS loading buffer. A non-reducing SDS loading buffer was used, as non-reducing conditions allow the visualization of any disulfide-linked dimers (33). Specifically, non-reducing buffers do not contain 2-mercaptoethanol (2-ME) or dithiothreitol (DTT), which can reduce disulphide bridges in proteins. In order to perform western blot analysis, the purified sample was diluted until the final concentration of $1 \mu \mathrm{g}$ of albumin was achieved. Afterwards, an aliquot containing the diluted purified sample and a $2 \mathrm{X}$ non-reducing loading buffer was prepared, heated in boiling water for $3 \mathrm{~min}$ and separated by SDS-PAGE, using a polyacrylamide gel $8 \%(\mathrm{w} / \mathrm{v})$. After $1 \mathrm{~h}$ of electrophoresis at $150 \mathrm{~V}$, proteins were transferred onto polyvinylidenedifluoride (PVDF) membranes (Bio-Rad Laboratories, Hercules, CA, USA) and blocked overnight with 5\% non-fat milk in TBST (13 mmol/1 Tris, $150 \mathrm{mmol} / 1 \mathrm{NaCl}(\mathrm{pH} 7.5)$ solution, containing also $0.2 \%$ Tween-20 (TBSTMS).

The membranes were then incubated in a shaker for $1 \mathrm{~h}$ at room temperature with a goat anti-human albumin antibody diluted 1:5,000 in TBSTMS. Following extensive washes in TBST ( 5 times for $5 \mathrm{~min}$ ) the blots were incubated for $30 \mathrm{~min}$ with anti-goat IgG secondary antibody (1:3,000 dilution). The membranes washed in TBST (3 times for $15 \mathrm{~min}$ ) and the labeled protein bands were visualized by enhanced chemiluminescence (Bio-Rad Laboratories) and subsequent exposure to XAR 5 film (Fujifilm Corp., Tokyo, Japan). The protein bands were quantified using Alpha View quantification software (Alpha Innotech, San Leandro, CA, USA). Each sample was analyzed in triplicate.

Statistical analysis. The statistical analysis was based on one-way ANOVA followed by Dunnett's test for multiple pairwise comparisons. The statistical significance level was set at $\mathrm{P}<0.05$. Correlations between oxidized albumin and the other oxidative stress markers were examined by Spearman's correlation analysis. The level of significance was also set at $\mathrm{P}<0.05$. For all statistical analyses, SPSS version 20.0 (SPSS, Inc., Chicago, IL, USA) was used. Data are presented as the means \pm standard error of the mean.

\section{Results}

Western blot analysis was used for the assessment of albumin monomers and dimers. Monomer bands were displayed at $\sim 55 \mathrm{kDa}$, while dimer formation appeared at approximately $110 \mathrm{kDa}$ (Fig. 1). The lower molecular weight of the dimer bands compared to the theoretical one has been observed previously (29).

In each sample, the percentage ratio of dimers to monomers was quantified and considered as marker of HSA oxidation. The percentage change of oxidized HSA (i.e., the ratio of dimers to monomers) at 24,48 and $72 \mathrm{~h}$ post-race compared to pre-race is shown in Fig. 2. There were not statistically significant differences between time points post-race and pre-race (Fig. 2).

Similarly, the percentage ratio of dimers to the total amount of HSA [i.e., dimers/(dimers + monomers)] was also quantified in order to obtain a clearer view regarding the changes of the protein after the race (Table I). Also, in this case, there were
Table I. Percentage of dimer HSA to total HSA of athletes at all time points.

\begin{tabular}{lrrrr}
\hline & \multicolumn{4}{c}{ Oxidized/total HSA levels (\%) } \\
\cline { 2 - 5 } & \multicolumn{4}{c}{ Time point (h) } \\
\cline { 2 - 5 } Individual & Pre-race & 24 & 48 \\
\hline 1 & 36.59 & 34.12 & 30.19 & 27.42 \\
2 & 39.06 & 34.27 & 37.31 & 44.01 \\
3 & 45.37 & 44.84 & 38.53 & 29.22 \\
4 & 28.96 & 37.98 & 30.38 & 37.12 \\
5 & 36.43 & 31.74 & 28.09 & 22.88 \\
6 & 36.58 & 36.04 & 43.06 & 34.82 \\
7 & 38.38 & 35.12 & 33.47 & 39.18 \\
8 & 21.95 & 22.92 & 25.51 & 24.46 \\
9 & 25.44 & 24.68 & 27.93 & 15.42 \\
10 & 39.51 & 41.73 & 40.26 & 39.90 \\
11 & 30.11 & 32.19 & 36.51 & 37.55 \\
12 & 35.11 & 33.60 & 32.74 & 35.95 \\
Mean & $34.95 \pm 2.02$ & $34.60 \pm 1.89$ & $34.17 \pm 1.36$ & $32.83 \pm 2.53$ \\
\hline
\end{tabular}

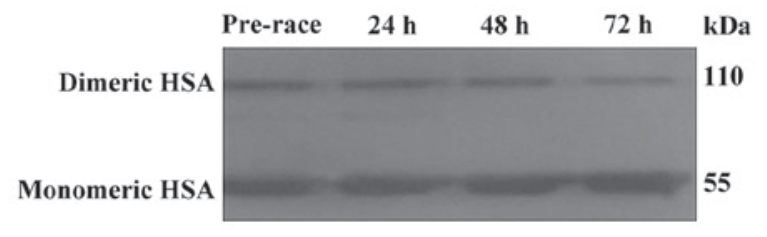

Figure 1. Representative image for the detection of monomeric and dimeric serum albumin (HSA) by western blot analysis. Specifically, it is shown the HSA from individual no. 2 at all time points (pre-race and 24, 48 and $72 \mathrm{~h}$ post-race). Albumin was obtained by Blue sepharose column chromatography and subjected to SDS-PAGE $8 \%(w / v)$ gel, under non-reducing conditions prior to immunoblotting analysis.

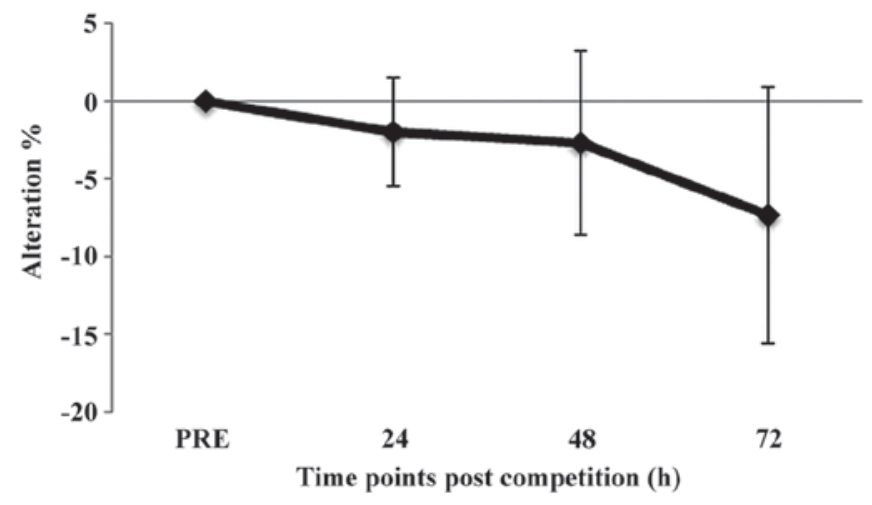

Figure 2. Percentage alteration of oxidized HSA (i.e., dimers/monomers ratio) in the plasma samples from the athletes participating in the mountain marathon race at 24,48 and $72 \mathrm{~h}$ post-race compared with pre-race (PRE) samples. The values indicate the means \pm standard error of the mean.

no statistically significant differences in the values post-race compared to those pre-race. 
Table II. Correlation analysis between percentage changes of HSA oxidation at 24, 48 and $72 \mathrm{~h}$ post-race compared to pre-race and the corresponding percentage changes of PC, TBARS, GSH, sORP and cORP oxidative stress markers.

\begin{tabular}{cccccccrr}
\hline & Time point $(\mathrm{h})$ & PC & TBARS & GSH & TAC & CAT & sORP & cORP \\
\hline HSA & 24 & $0.769^{\mathrm{a}}$ & -0.329 & 0.448 & -0.098 & -0.147 & $0.58^{\mathrm{a}}$ & $-0.601^{\mathrm{a}}$ \\
& 48 & $0.867^{\mathrm{b}}$ & 0.336 & 0.063 & -0.329 & -0.231 & 0.448 & $-0.657^{\mathrm{a}}$ \\
& 72 & $0.860^{\mathrm{b}}$ & -0.091 & -0.140 & -0.007 & -0.524 & -0.105 & 0.056 \\
\hline
\end{tabular}

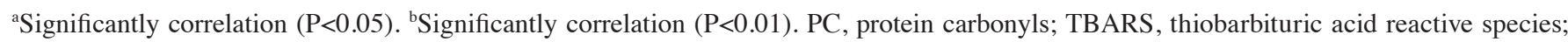
GSH, glutathione; TAC, total antioxidant capacity; CAT, catalase activity; sORP, static oxidation-reduction potential; cORP, capacity oxidation reduction potential.

In a previous study, in the samples, we assessed the percentage changes at 24,48 and $72 \mathrm{~h}$ post-race in the oxidative stress markers, namely PC levels, thiobarbituric acid reactive species (TBARS) levels, glutathione (GSH) levels, total antioxidant capacity (TAC), catalase (CAT) activity, static oxidation-reduction potential (sORP) and capacity oxidation-reduction potential (cORP) compared to those at pre-race (31). In order to determine whether the changes in HSA oxidation are associated with any other marker, a correlation analysis was carried out between the percentage changes of HSA at time points post-race and the percentage changes of the other oxidative stress biomarkers (Table II). The results revealed that there was a significantly high correlation between HSA oxidation and PC at all three time points post-race (Table II). There were also moderate, yet significant correlations between HSA oxidation and sORP at $24 \mathrm{~h}$ post-race, as well as with cORP at 24 and $48 \mathrm{~h}$ post-race (Table II).

In our previous study, we demonstrated that there were great differences in the percentage changes post-race of oxidative stress markers (including PC) between different individuals (31). Thus, it was suggested that some markers should be examined individually in order to make safer conclusions and apply the appropriate interventions (25). Similarly, the changes in HSA oxidation (i.e., dimer/monomer percentage) post-race were also examined individually (Figs. 3 and 4). Moreover, since HSA exhibited a high correlation with PC, showing the oxidation of total protein in plasma, the individual changes in HSA post-race were displayed along with the individual changes in PC (Figs. 3 and 4). For this individual analysis, the criteria used for determining whether there was an increase (or decrease) in HSA oxidation post-race compared to pre-race were: i) HSA oxidation should be increased (or decreased) at all time points post-race compared to pre-race; and ii) HSA oxidation should be increased (or decreased) $>20 \%$ at least at one time point post-race compared to pre-race. This individual analysis indicated that in some athletes (nos. 6, 8 and 11), HSA oxidation was increased post-race compared to pre-race (Figs. 3 and 4). However, in other athletes (nos. 1, 3 and 5), HSA oxidation post-race was lower than that at pre-race (Fig. 3). In 6 athletes (nos. 2, 4, 7, 9, 10 and 12), HSA oxidation exhibited no changes between pre- and post-exercise (Figs. 3 and 4). The individual comparison between HSA oxidation and PC indicated that in 6 athletes (individuals no. 2, 3, 7, 8, 9 and 10) the changes of the two markers at time points post-race compared to pre-race followed the same trend (i.e., increase or decrease) (Figs. 3 and 4). The two markers are considered to follow the same trend if the difference in the percentage change between them at each time point post-race was $<20 \%$. However in 2 athletes (individuals no. 1 and 11), HSA was oxidized more than the total protein, while in others (individuals no. 4, 5, 6 and 12) HSA was more protected from ROS compared with the total protein (Figs. 3 and 4).

\section{Discussion}

In the present study, the changes in HSA oxidation were examined following strenuous exercise, such as a mountain-marathon race. Specifically, blood samples were collected from 12 experienced male mountain-marathon runners who participated in a $103 \mathrm{~km}$ mountain marathon race, the 'Olympus Mythical Trail'. Blood samples were collected from athletes at four different time points, pre-race and at 24,48 and $72 \mathrm{~h}$ post-race, in order to assess the alterations in their redox status by quantifying HSA dimer formation, that is, HSA oxidation.

HSA is the most abundant protein in plasma, as it makes up approximately $55 \%$ of the total serum protein content (34). The function of HSA is based on non-specific binding sites, which allow it to transfer a variety of molecules throughout the circulatory system. Specifically, it binds water, cations (e.g., $\mathrm{Ca}^{2+}, \mathrm{Na}^{+}$ and $\mathrm{K}^{+}$), fatty acids, hormones, pharmaceuticals and vitamins. The main function of albumin is the regulation of the colloidal osmotic pressure of blood (35). Thus, many of the enzymatic activities of HSA are connected with the binding of metabolic products, which affects the related metabolic pathways (36).

HSA contains a total of 35 cysteine residues from which 34 are involved in intramolecular disulfide bonds and only cysteine34 (Cys34) remains free (37). It is estimated that approximately $70 \%$ of the total free thiol content in plasma exists in HSA Cys34 (38). This pool of thiol compounds in plasma gives rise to thiol exchange reactions, leading to a number of disulfide bonds, and thus to the formation of dimers acting as antioxidants by scavenging hydroxyl or other radicals through the reduced sulfhydryl group (39). The dimerization site proved to be the Cys 34 by forming a disulfide bridge between two albumin molecules (40). According to Ogasawara et al (29), the formed dimers as a result to ROS exposure can be used as an oxidative stress marker. As shown by us and others, the formation of HSA dimers was also displayed following exhaustive exercise-induced oxidative stress $(20,41)$. It is noteworthy 
A

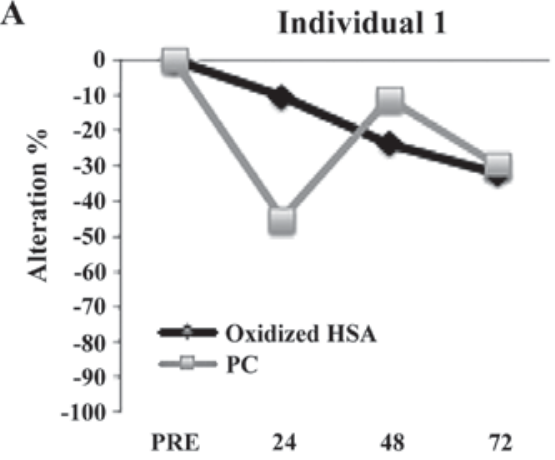

Time points post competition (h)

C

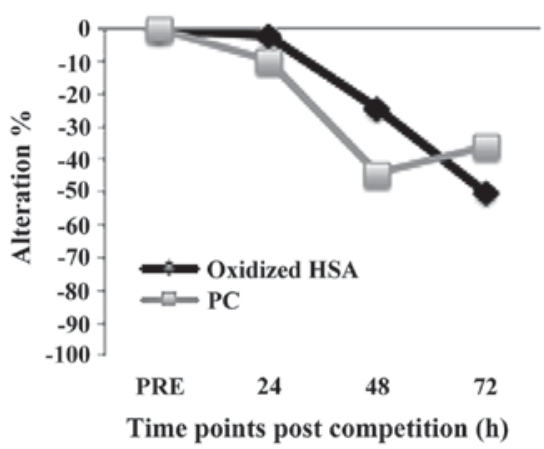

$\mathbf{E}$

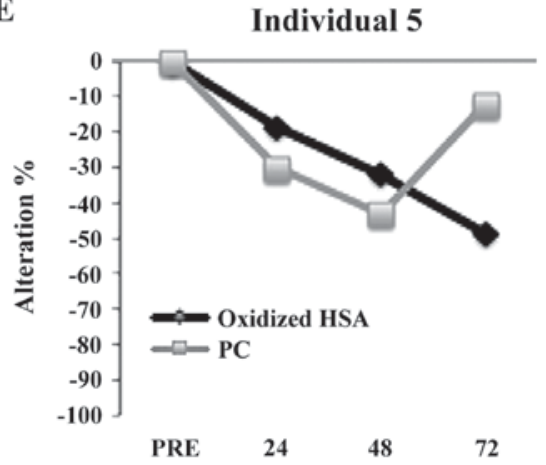

Time points post competition (h)
B

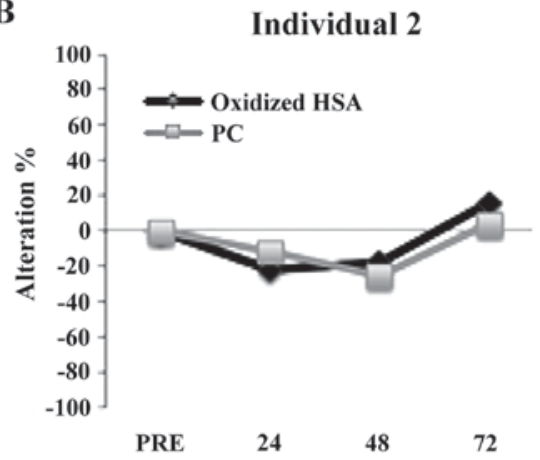

Time points post competition (h)

D

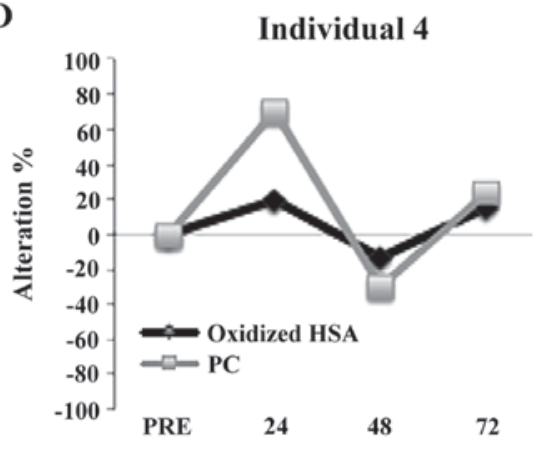

Time points post competition (h)

$\mathbf{F}$

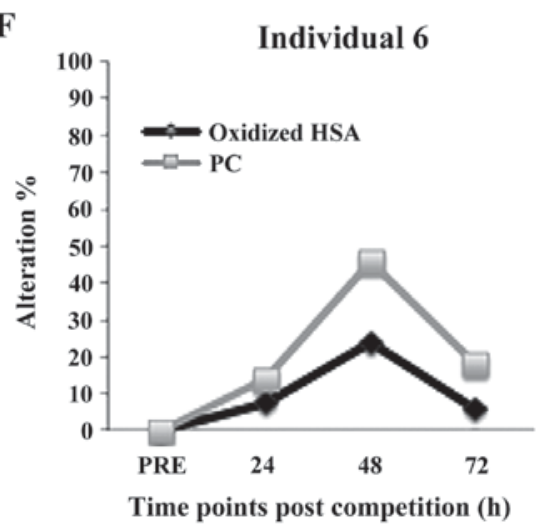

Figure 3. Percentage changes in HSA oxidation (i.e., dimers/monomers ratio), and PC levels of individuals 1-6 at 24, 48 and 72 h post-race time points, compared with pre-race (PRE).

that the exercise-induced increase in ROS activates adaptive responses through signaling pathways regulated by thiol status, including reduced Cys34 of HSA (28,42-44). Additionally, changes in the thiol redox status induce the expression of nuclear factor $-\kappa \mathrm{B}(\mathrm{NF}-\kappa \mathrm{B})$ and activator protein-1 (AP-1), leading to an increase in the levels of the cytokines, IL- 6 and TNF- $\alpha(42,45)$. Both of these cytokines not only affect muscle regeneration, but also the development of tolerance following ROS-induced muscle damage. In general, the oxidation of a protein and more specifically HSA following ROS exposure, can lead to a loss of its structural and catalytic function (46). Oxidation and thus dimerization of HSA impedes its activity, as the dimer is more rigid, rendering substrate binding less favorable (47). Specifically, the oxidation of HSA has been observed to decrease both the ligand binding property of site II and the esterase-like activity of HSA, most probably due to conformational changes in subdomain IIIA (47). In addition, HSA has been shown to exhibit an intristic enolase activity towards dihydrotestosterone that is reduced upon dimerization (36). It is known that when oxidized proteins are accumulated in the cells, degradation systems are then activated (48). Moreover, Kawakami et al reported that the oxidation of the major antioxidant thiol group Cys34 of HSA results in reduced scavenging activity against highly ROS produced after exercise such as hydroxyl radicals, which may affect athletes' recovery (49). Therefore, it is obvious that excessive HSA oxidation should be prevented. The significant interplay between HSA and oxidative stress necessitates the investigation of HSA oxidation, particularly in athletes undergoing demanding exercise.

The present results indicated that on average, HSA oxidation was not increased at any time point post-race compared 
A

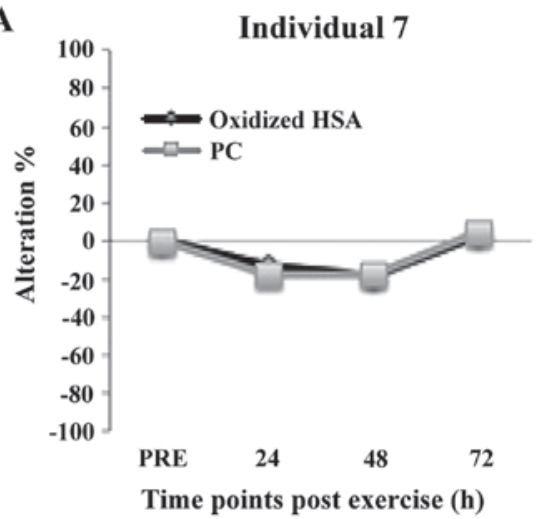

C

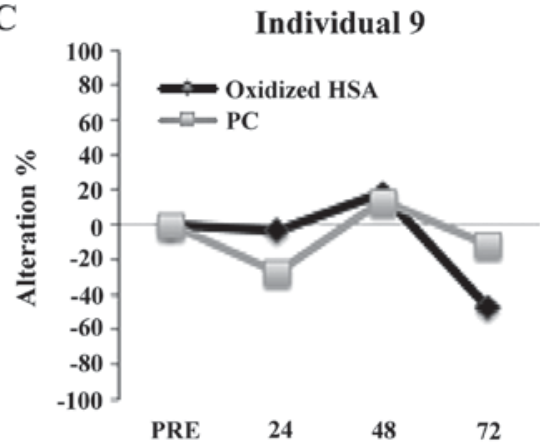

Time points post competition (h)
B
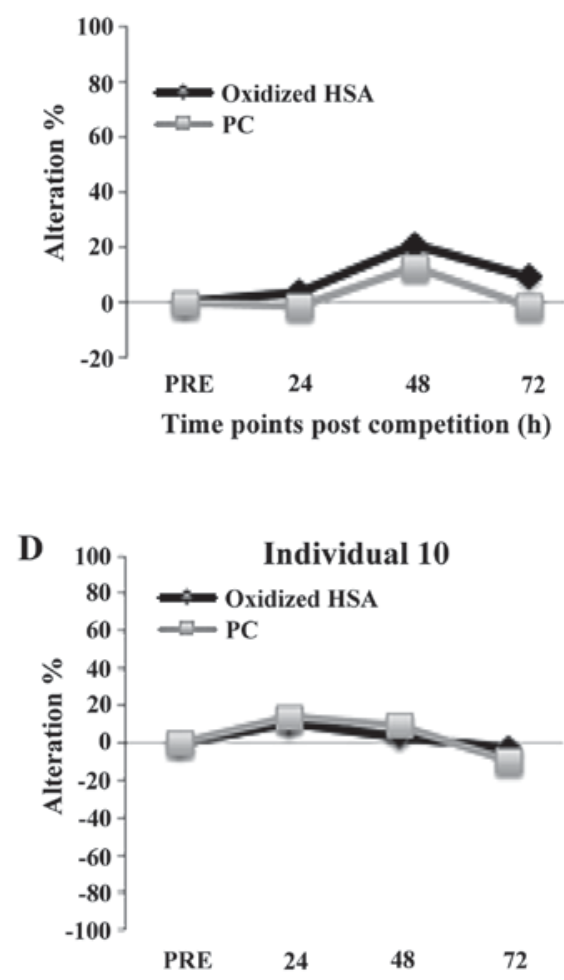

Time points post competition (h)
$\mathbf{E}$

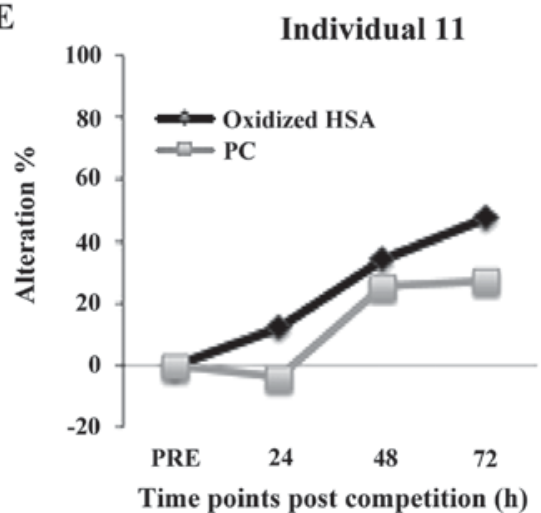

F

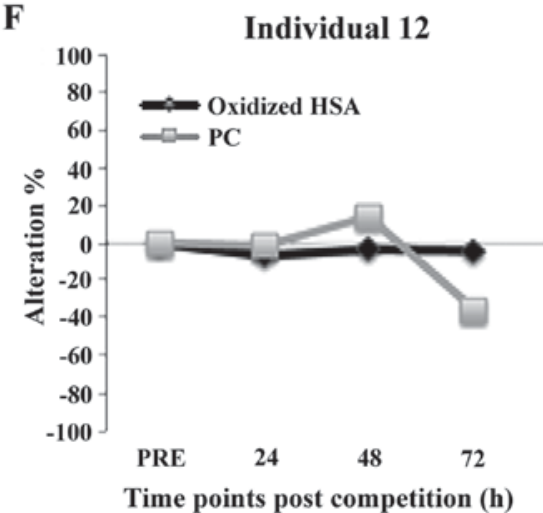

Figure 4. Percentage changes in HSA oxidation (i.e., dimers/monomers ratio), and PC levels of individuals 7-12 at 24,48 and $72 \mathrm{~h}$ post-race time points, compared with pre-race (PRE).

to that at pre-race. Although there was no oxidation of thiols of HSA post-race compared to pre-race, thiol groups of glutathione of the same samples were oxidized as previously demonstrated (31). Therefore, HSA seems to be more protected against oxidation than GSH, since the latter may be involved more in ROS scavenging. Our results were in agreement with those of our previous study on the same samples, which have shown that there was no difference in the oxidation of total protein in plasma between pre and post-race (31). However, other studies have shown an increase in HSA oxidation following exercise $(20,28,41)$. As we have reported previously, this discrepancy between different studies regarding protein oxidation may be explained by the inter-individual variation of protein oxidation after strenuous exercise (31). Likewise, HSA oxidation exhibited great variability, since it was increased in 3 athletes, decreased in 3 athletes and had no change in 6 athletes post-race compared to pre-race.

The samples used in the present study were also analyzed in one of our previous studies by measuring other oxidative stress markers, such as PC, TBARS, TAC, GSH, CAT, sORP and cORP (31). Thus, HSA oxidation was assessed by quantifying dimers, so as to compare its levels with the other performed assays and make conclusions about its usefulness as a biomarker for strenuous exercise-induced oxidative stress. The results revealed a significantly high correlation between HSA oxidation and PC (i.e., oxidation of total protein) at all time points post-race. The aforementioned correlation was expected, since the increased concentration of PC following 
exercise has been suggested to be mainly derived from the oxidation of HSA making up approximately $55 \%$ of total serum protein, as well as of other major proteins $(50,51)$. In addition, there was a significant positive correlation between HSA oxidation and sORP at $24 \mathrm{~h}$ post-race, and a negative correlation with cORP at 48 and $72 \mathrm{~h}$ post-race, respectively. These two novel markers have been used previously in several of our studies for assessing exercise-induced oxidative stress (8-11). The above correlations were meaningful, since sORP increased values correspond to higher oxidative stress levels, as it represents the integrated balance of oxidants and reductants, while cORP is a measure of antioxidant reserve available in the body's system.

As mentioned above, HSA oxidation exhibited a great variation between different athletes. Moreover, HSA oxidation had a high correlation with $\mathrm{PC}$, that is, with the oxidation of total plasma protein. Thus, each athlete was examined separately in order to compare the changes in HSA oxidation and PC levels, since HSA constitutes approximately $55 \%$ of the total protein content in plasma as mentioned before. Several studies have demonstrated that albumin, as well as fibrinogen are the main protein targets of oxidative stress in plasma (50-53). Moreover, since HSA represents about the half of the total protein content in plasma, a similar trend of PC and HSA oxidation levels in each individual was expected post-race. However, our results indicated that protein oxidation post-race in several athletes exhibited great differences compared to PC levels. Specifically, the results revealed that similar oxidation levels between $\mathrm{PC}$ and HSA at all time points post-race were displayed in only 6 out of 12 runners. Thus, in these individuals, it seems that HSA oxidation post-race was not affected differently than the other plasma proteins. However, the remaining 6 athletes exhibited great differences in the changes between PC and HSA oxidation at one or more time points post-race. It was remarkable, that in 4 athletes, HSA was more protected from oxidation than the other plasma proteins. These results supported the hypothesis of Madian and Regnier (54), who suggested that despite the abundance of HSA in plasma, it is not so vulnerable to oxidation as other proteins, such as fibrinogen (53). However, in 2 athletes, HSA oxidation was higher compared to total plasma proteins. To sum up, all these findings suggested that the measurement of only PC is not sufficient to make conclusions about HSA oxidation, and thus it is needed to be examined separately after exercise.

Moreover, in a previous study, we demonstrated that in some of these athletes, instead of protein oxidation post-race, there was protein reduction (31). Similarly, albumin in some of these athletes (individuals no. 1,3 and 5) exhibited a decrease in oxidation and not an increase post-race. The manifestation of reductive stress instead of oxidative one, particularly after eccentric exercise, has been reported by us, as well as by others $(8,55)$. This intriguing effect can be explained by the high complexity of the regulation of redox homeostasis in human, since many genetic, physiological, biochemical or dietary factors may affect the final outcome of oxidant stimuli (56-58).

The changes in the ratio of dimer to total HSA post-exercise compared to pre-exercise showed the same trend with the ratio of dimer to monomer HSA, that is, in each athlete both ratios either decreased or increased post exercise. Similar to the ratio of dimer to monomer HSA, the ratio of dimer to total HSA exhibited great variability, from 15.42 to $45.37 \%$, between different individuals at all time points post exercise. This variability in HSA oxidation may indicate differences in its functionality, that is, individuals with higher HSA oxidation levels are likely to have lower HSA activity and vice versa. As mentioned above, lower HSA functionality may affect its binding capacity for several ligands, and thus there may be need for a dietary intervention in order to improve the athletes' redox status particularly following strenuous exercise.

In conclusion, the present results support the notion that the assessment of HSA dimers, that is, HSA oxidation may be used as a complementary marker of oxidative stress after exhaustive exercise, particularly as regards the effects on proteins. This inference is supported by the correlation between HSA oxidation and other oxidative stress markers, such as PC, sORP and cORP. In general, thiol levels have been suggested as a marker of oxidative stress (35). However, the assessment of oxidative stress using low molecular weight thiols is difficult, as they are susceptible to oxidative damage and their measurement, particularly in blood, is not easy. Thus, the measurement of stable oxidized thiol groups, such as albumin dimers, is more practical, taking into account that $70 \%$ of the total free thiol content in plasma exists in HSA (29). Moreover, the fact that in some athletes the changes in HSA oxidation post-exercise did not follow the changes of $\mathrm{PC}$, suggested the need for assessing both of these markers in order to reach a more confident conclusion about protein oxidation in plasma and make the appropriate dietary interventions. Finally, to the best of our knowledge, this study demonstrated for the first time that in some athletes, HSA was reduced instead of being oxidized post-exercise, highlighting the need for investigating further the individual impact on HSA oxidation and generally in redox status. The understanding of the inter-individual variability of HSA oxidation may prove to be useful for applying the appropriate interventions through nutrition and supplementation to athletes participating in demanding exercise such as mountain marathon race $(7,12)$.

The need for a separate analysis of HSA oxidation is supported by its abundance in plasma and its important physiological roles, which are disturbed after oxidation. This individual approach to HSA oxidation may help athletes to better improve immediate recovery process and consequently health status and performance.

\section{References}

1. Alessio HM, Hagerman AE, Fulkerson BK, Ambrose J, Rice RE and Wiley RL: Generation of reactive oxygen species after exhaustive aerobic and isometric exercise. Med Sci Sports Exerc 32: 1576-1581, 2000.

2. Sen CK: Oxidants and antioxidants in exercise. J Appl Physiol (1985) 79: 675-686, 1995.

3. Halliwell B: The wanderings of a free radical. Free Radic Biol Med 46: 531-542, 2009.

4. Ghosh J and Myers CE: Inhibition of arachidonate 5-lipoxygenase triggers massive apoptosis in human prostate cancer cells. Proc Natl Acad Sci USA 95: 13182-13187, 1998.

5. Valko M, Leibfritz D, Moncol J, Cronin MTD, Mazur M and Telser $\mathrm{J}$ : Free radicals and antioxidants in normal physiological functions and human disease. Int J Biochem Cell Biol 39: 44-84, 2007.

6. Orient A, Donkó A, Szabó A, Leto TL and Geiszt M: Novel sources of reactive oxygen species in the human body. Nephrol Dial Transplant 22: 1281-1288, 2007.

7. Veskoukis AS, Tsatsakis AM and Kouretas D: Dietary oxidative stress and antioxidant defense with an emphasis on plant extract administration. Cell Stress Chaperones 17: 11-21, 2012. 
8. Stagos D, Goutzourelas N, Ntontou A-M, Kafantaris I, Deli CK, Poulios A, Jamurtas AZ, Bar-Or D and Kouretas D: Assessment of eccentric exercise-induced oxidative stress using oxidation-reduction potential markers. Oxid Med Cell Longev 2015: 204615, 2015.

9. Stagos D, Goutzourelas N, Bar-Or D, Ntontou AM, Bella E, Becker AT, Statiri A, Kafantaris I and Kouretas D: Application of a new oxidation-reduction potential assessment method in strenuous exercise-induced oxidative stress. Redox Rep 20: 154-162, 2014.

10. 10. Spanidis Y, Goutzourelas N, Stagos D, Mpesios A, Priftis A, Bar-Or D, Spandidos DA, Tsatsakis AM, Leon G and Kouretas D: Variations in oxidative stress markers in elite basketball players at the beginning and end of a season. Exp Ther Med 11: 147-153, 2016.

11. Spanidis Y, Mpesios A, Stagos D, Goutzourelas N, Bar-Or D, Karapetsa M, Zakynthinos E, Spandidos DA, Tsatsakis AM, Leon $\mathrm{G}$, et al: Assessment of the redox status in patients with metabolic syndrome and type 2 diabetes reveals great variations. Exp Ther Med 11: 895-903, 2016.

12. Kerasioti E, Kiskini A, Veskoukis A, Jamurtas A, Tsitsimpikou C, Tsatsakis AM, Koutedakis Y, Stagos D, Kouretas D and Karathanos V: Effect of a special carbohydrate-protein cake on oxidative stress markers after exhaustive cycling in humans. Food Chem Toxicol 50: 2805-2810, 2012.

13. Farrugia A: Albumin usage in clinical medicine: Tradition or therapeutic? Transfus Med Rev 24: 53-63, 2010.

14. Malik A, Al-Senaidy A, Skrzypczak-Jankun E and Jankun J: Isolation and characterization of serum albumin from Camelus dromedarius. Exp Ther Med 6: 519-524, 2013.

15. Kragh-Hansen U, Pedersen AO, Galliano M, Minchiotti L, Brennan SO, Tárnoky AL, Franco MH and Salzano FM: High-affinity binding of laurate to naturally occurring mutants of human serum albumin and proalbumin. Biochem J 320: 911-916, 1996

16. Pawar SK, Punith R, Naik RS and Seetharamappa J: Spectroscopic and molecular modeling approaches to investigate the binding of proton pump inhibitors to human serum albumin. J Biomol Struct Dyn: Nov 18, 2016 (Epub ahead of print).

17. Ishida K, Sawada N and Yamaguchi M: Expression of albumin in bone tissues and osteoblastic cells: Involvement of hormonal regulation. Int J Mol Med 14: 891-895, 2004.

18. Doweiko JP and Nompleggi DJ: Role of albumin in human physiology and pathophysiology. JPEN J Parenter Enteral Nutr 15: 207-211, 1991

19. Halliwell B: Albumin - an important extracellular antioxidant? Biochem Pharmacol 37: 569-571, 1988.

20. Imai H, Hayashi T, Negawa T, Nakamura K, Tomida M, Koda K, Tajima T, Koda Y, Suda K and Era S: Strenuous exercise-induced change in redox state of human serum albumin during intensive kendo training. Jpn J Physiol 52: 135-140, 2002.

21. Davies KJ: Protein damage and degradation by oxygen radicals I. general aspects. J Biol Chem 262: 9895-9901, 1987.

22. Davies KJ, Delsignore ME and Lin SW: Protein damage and degradation by oxygen radicals. II. Modification of amino acids. J Biol Chem 262: 9902-9907, 1987.

23. Davies KJ and Delsignore ME: Protein damage and degradation by oxygen radicals. III. Modification of secondary and tertiary structure. J Biol Chem 262: 9908-9913, 1987.

24. Davies KJ, Lin SW and Pacifici RE: Protein damage and degradation by oxygen radicals. IV. Degradation of denatured protein. J Biol Chem 262: 9914-9920, 1987.

25. Alvarez B, Ferrer-Sueta G, Freeman BA and Radi R: Kinetics of peroxynitrite reaction with amino acids and human serum albumin. J Biol Chem 274: 842-848, 1999.

26. Carballal S, Radi R, Kirk MC, Barnes S, Freeman BA and Alvarez B: Sulfenic acid formation in human serum albumin by hydrogen peroxide and peroxynitrite. Biochemistry 42 : 9906-9914, 2003.

27. Gutteridge JM: Antioxidant properties of the proteins caeruloplasmin, albumin and transferrin. A study of their activity in serum and synovial fluid from patients with rheumatoid arthritis. Biochim Biophys Acta 869: 119-127, 1986.

28. Lamprecht M, Greilberger JF, Schwaberger G, Hofmann P and Oettl K: Single bouts of exercise affect albumin redox state and carbonyl groups on plasma protein of trained men in a workload-dependent manner. J Appl Physiol 1985 104: 1611-1617, 2008
29. Ogasawara Y, Namai T, Togawa T and Ishii K: Formation of albumin dimers induced by exposure to peroxides in human plasma: A possible biomarker for oxidative stress. Biochem Biophys Res Commun 340: 353-358, 2006.

30. Veskoukis AS, Kyparos A, Stagos D and Kouretas D: Differential effects of xanthine oxidase inhibition and exercise on albumin concentration in rat tissues. Appl Physiol Nutr Metab 35: 244-250, 2010

31. Spanidis Y, Stagos D, Orfanou M, Goutzourelas N, Bar-Or D, Spandidos D and Kouretas D: Variations in Oxidative Stress Levels in 3 Days Follow-up in Ultramarathon Mountain Race Athletes. J Strength Cond Res 31: 582-594, 2017.

32. Dumas BT, Watson WA and Biggs HG: Albumin standards and the measurement of serum albumin with bromcresol green. 1971 Clin Chim Acta 258: 21-30, 1997.

33. Sheffield WP, McCurdy TR and Bhakta V: Fusion to albumin as a means to slow the clearance of small therapeutic proteins using the Pichia pastoris expression system: A case study. Methods Mol Biol 308: 145-154, 2005

34. Anderson NL and Anderson NG: The human plasma proteome: History, character, and diagnostic prospects. Mol Cell Proteomics 1: 845-867, 2002.

35. Quinlan GJ, Martin GS and Evans TW: Albumin: Biochemical properties and therapeutic potential. Hepatology 41: 1211-1219, 2005.

36. Drmanovic Z, Voyatzi S, Kouretas D, Sahpazidou D, Papageorgiou A and Antonoglou O: Albumin possesses intrinsic enolase activity towards dihydrotestosterone which can differentiate benign from malignant breast tumors. Anticancer Res 19 (5B): 4113-4124, 1999.

37. Theodore Peters Jr: All About Albumin: Biochemistry, Genetics, and Medical Applications. 1st edition. Academic Press, San Diego, CA, 1997.

38. Turell L, Carballal S, Botti H, Radi R and Alvarez B: Oxidation of the albumin thiol to sulfenic acid and its implications in the intravascular compartment. Braz J Med Biol Res 42: 305-311, 2009.

39. Roche M, Rondeau P, Singh NR, Tarnus E and Bourdon E: The antioxidant properties of serum albumin. FEBS Lett 582: 1783-1787, 2008

40. Naldi M, Baldassarre M, Nati M, Laggetta M, Giannone FA, Domenicali M, Bernardi M, Caraceni P and Bertucci C: Mass spectrometric characterization of human serum albumin dimer: A new potential biomarker in chronic liver diseases. J Pharm Biomed Anal 112: 169-175, 2015.

41. Veskoukis AS, Nikolaidis MG, Kyparos A, Kokkinos D, Nepka C, Barbanis S and Kouretas D: Effects of xanthine oxidase inhibition on oxidative stress and swimming performance in rats. Appl Physiol Nutr Metab 33: 1140-1154, 2008.

42. Ji LL, Gomez-Cabrera M-C and Vina J: Exercise and hormesis: Activation of cellular antioxidant signaling pathway. Ann N Y Acad Sci 1067: 425-435, 2006.

43. Melikoglu MA, Kaldirimci M, Katkat D, Sen I, Kaplan I and Senel K: The effect of regular long term training on antioxidant enzymatic activities. J Sports Med Phys Fitness 48: 388-390, 2008.

44. Zembron-Lacny A, Slowinska-Lisowska M and Ziemba A: Integration of the thiol redox status with cytokine response to physical training in professional basketball players. Physiol Res 59: 239-245, 2010

45. Kerksick C and Willoughby D: The antioxidant role of glutathione and $\mathrm{N}$-acetyl-cysteine supplements and exercise-induced oxidative stress. J Int Soc Sports Nutr 2: 38-44, 2005.

46. Levine RL and Stadtman ER: Oxidative modification of proteins during aging. Exp Gerontol 36: 1495-1502, 2001.

47. Anraku M, Yamasaki K, Maruyama T, Kragh-Hansen U and Otagiri M: Effect of oxidative stress on the structure and function of human serum albumin. Pharm Res 18: 632-639, 2001

48. Jung T, Höhn A and Grune T: The proteasome and the degradation of oxidized proteins: Part II-protein oxidation and proteasomal degradation. Redox Biol 2: 99-104, 2014.

49. Kawakami A, Kubota K, Yamada N, Tagami U, Takehana K, Sonaka I, Suzuki E and Hirayama K: Identification and characterization of oxidized human serum albumin. A slight structural change impairs its ligand-binding and antioxidant functions. FEBS J 273: 3346-3357, 2006.

50. Margonis K, Fatouros IG, Jamurtas AZ, Nikolaidis MG, Douroudos I, Chatzinikolaou A, Mitrakou A, Mastorakos G, Papassotiriou I, Taxildaris K, et al: Oxidative stress biomarkers responses to physical overtraining: Implications for diagnosis. Free Radic Biol Med 43: 901-910, 2007. 
51. Michailidis Y, Jamurtas AZ, Nikolaidis MG, Fatouros IG, Koutedakis Y, Papassotiriou I and Kouretas D: Sampling time is crucial for measurement of aerobic exercise-induced oxidative stress. Med Sci Sports Exerc 39: 1107-1113, 2007.

52. Shacter E, Williams JA, Lim M and Levine RL: Differential susceptibility of plasma proteins to oxidative modification: Examination by western blot immunoassay. Free Radic Biol Med 17: 429-437, 1994

53. Michelis R, Gery R, Sela S, Shurtz-Swirski R, Grinberg N, Snitkovski T, Shasha SM and Kristal B: Carbonyl stress induced by intravenous iron during haemodialysis. Nephrol Dial Transplant 18: 924-930, 2003.

54. Madian AG and Regnier FE: Profiling carbonylated proteins in human plasma. J Proteome Res 9: 1330-1343, 2010.
55. Margaritelis NV, Kyparos A, Paschalis V, Theodorou AA, Panayiotou G, Zafeiridis A, Dipla K, Nikolaidis MG and Vrabas IS: Reductive stress after exercise: The issue of redox individuality. Redox Biol 2: 520-528, 2014.

56. Simoneau JA and Bouchard C: Human variation in skeletal muscle fiber-type proportion and enzyme activities. Am J Physiol 257: E567-E572, 1989.

57. Kant AK and Graubard BI: Ethnic and socioeconomic differences in variability in nutritional biomarkers. Am J Clin Nutr 87: 1464-1471, 2008

58. Rankinen T and Bouchard C: Gene-physical activity interactions: Overview of human studies. Obesity (Silver Spring) 16 (Suppl 3): S47-S50, 2008 